\title{
DESAFIOS ENFRENTADOS POR PROFESSORES NA IMPLEMENTAÇÃO DE ATIVIDADES INVESTIGATIVAS NAS AULAS DE CIÊNCIAS
}

\section{Challenges faced by teachers in the implementation of inquiry activities in science classes}

\author{
Ana Maria Santos Gouw ${ }^{1}$. Fernanda Franzolin ${ }^{2}$. \\ Marcela Elena Fejes ${ }^{3}$
}

\begin{abstract}
Resumo: Apesar da associação entre investigação e Ensino de Ciências ser idealizada desde o início do século XX, não necessariamente consiste em uma prática amplamente utilizada nas escolas, nem aplicada com os mesmos objetivos. Desse modo, considera-se relevante que pesquisadores se debrucem sobre o contexto brasileiro e verifiquem como essa união ocorre. Este trabalho investigou quais são os desafios enfrentados e as estratégias utilizadas, por dois professores diferentes, durante a implementação de um único projeto investigativo, para se adequarem à realidade da escola, nível de ensino e ao contexto cultural existente. Os dados que subsidiaram esta pesquisa foram obtidos através de fontes primárias (entrevistas, questionários) e secundárias (portfólios, produções dos alunos, fichas, relatórios e observações). Percebeu-se que o mesmo projeto foi implementado de maneira bastante distinta entre um professor e outro, que realizaram adaptações de acordo com sua experiência profissional e com o nível de ensino de seus alunos.
\end{abstract}

Palavras-chave: Investigação e ensino de ciências. Aprendizagem participativa. Prática docente.

\begin{abstract}
Although the association between inquiry and science education has existed since the beginning of the 20th century, there is no guarantee that this practice frequently occurs in science classes and neither that it can also be used with the same purposes. Therefore, we think it is relevant that researchers investigate how this works in the Brazilian context. In this research, we investigated the challenges faced and the strategies used by two different teachers during the implementation of a single inquiry based project equating it to school reality, grade level and cultural context. Data collection was based on primary sources (interviews, questionnaires), and secondary sources (portfolios, student's assignments, cards, reports and observations). We noticed that both teachers implemented the same project in very different ways. The adaptations according to their professional experience and the students' grade level are presented here.
\end{abstract}

Keywords: Inquiry and science teaching. Participatory learning. Teachers practice.

\footnotetext{
${ }^{1}$ Faculdade de Educação, Universidade de São Paulo (USP), São Paulo, SP. Rua Basílio da Cunha, 60, São Paulo, SP, CEP 01544-000, Brasil. < anagouw@usp.br>.

${ }^{2}$ Centro de Educação Comunicação e Artes, Universidade Estadual de Londrina (UEL), Departamento de Educação, Londrina, PR, Brasil.

${ }^{3}$ Núcleo de Divulgação e Educação do Centro de Capacitação e Pesquisa em Meio Ambiente (CEPEMA), Escola Politécnica da USP, São Paulo, SP, Brasil.
} 
Gouw, A. M. S.; Franzolin, F.; Fejes, M. E.

\section{A investigação no ensino de Ciências}

Neste trabalho serão apresentados os resultados de um estudo que procurou investigar quais são os desafios enfrentados e estratégias utilizadas por professores durante a implementação de atividades investigativas nas aulas de Ciências. Sendo a investigação um dos elementos importantes desta pesquisa, serão aqui levantadas algumas considerações iniciais sobre esse tema, especialmente sobre sua contextualização e definição.

A associação entre ensino de Ciências e investigação não é novidade, ao menos em relação à sua idealização. Segundo Bybee (2000), esse movimento já era defendido no início do século XX, quando John Dewey se expressava a favor da inserção da investigação nas aulas de Ciências para propiciar o desenvolvimento de habilidades cognitivas, o aprendizado de conteúdos e o entendimento do processo de produção do conhecimento científico; e se estende até os dias atuais, como se pode verificar, por exemplo, nos parâmetros curriculares brasileiros, os Parâmetros Curriculares Nacionais (PCN) (BRASIL, 1997), e estadunidenses, os National Science Education Standards (NATIONAL RESEARCH COUNCIL, 1996).

Entretanto, Bybee (2000) aponta que nem sempre a união entre investigação e ensino de Ciências possui o mesmo objetivo e a mesma característica. Há aqueles que defendem a inserção da investigação, no ensino, como meio de os alunos aprenderem conteúdos científicos, e outros que a defendem como uma forma de os alunos compreenderem como o conhecimento científico é gerado e desenvolverem habilidades próprias do processo investigativo.

Quando a literatura aborda a questão investigação e ensino de Ciências, frequentemente se refere aos parâmetros curriculares estadunidenses, que dão grande ênfase à inserção da investigação dentro do ensino de Ciências, apesar de os mesmos não recomendarem esse como o único caminho para o ensino nessa área de conhecimento. Nesse documento, investigação é definida como "caminhos múltiplos pelos quais os cientistas estudam o mundo natural e propõem explicações baseadas nas evidências derivadas de seus trabalhos" (NATIONAL RESEARCH COUNCIL, 1996, p. 23, tradução nossa).

No National Science Education Standards (NATIONAL RESEARCH COUNCIL, 2000), a investigação é considerada como uma atividade escolar na qual os alunos podem gerar conhecimento para compreenderem como os cientistas estudam, e para entenderem as ideias científicas, ou seja, o conhecimento gerado pela Ciência. Desse modo, a investigação envolveria: a realização de observações, a proposição de questões, consultas bibliográficas e a outras fontes de informação, o planejamento de investigações, o uso de ferramentas para coletar, analisar e interpretar dados, a proposição de respostas, explicações e predições, e a comunicação dos resultados. Em sala de aula, os alunos podem participar de atividades que envolvam alguns aspectos do processo investigativo, para compreenderem como o conhecimento do mundo natural é construído, e para desenvolverem, aos poucos, a capacidade de conduzirem uma investigação completa (NATIONAL RESEARCH COUNCIL, 2000).

No contexto brasileiro, nos PCN, encontra-se a palavra investigação como sinônimo do estudo de um determinado tópico de interesse. O trabalho com o levantamento de questões, coleta de dados, registros, análise de dados e levantamento de conclusões, é recomendado já na Educação Infantil, por meio do Referencial Curricular Nacional da Educação Infantil (BRASIL, 1997, 1998). 
Bybee (2000) defende que a investigação no ensino de Ciências deve ser utilizada tanto como estratégia quanto como conteúdo. Desse modo, sua implementação em sala de aula seria importante não só como meio para que os alunos aprendam conteúdos científicos, mas, também, para que compreendam como se dá o processo de construção do conhecimento e desenvolvam habilidades inerentes ao processo investigativo. $\mathrm{O}$ autor ainda menciona que diferentes atividades podem ser utilizadas para a implementação da investigação no ensino de Ciências, tais como: atividades investigativas propostas pelos alunos fora dos laboratórios, experimentos conduzidos no laboratório direcionados pelo professor, ou discussões sobre textos que narram a condução de pesquisas realizadas por cientistas, julgando desejável a diversidade de atividades. Portanto, não há um único modo de se realizarem atividades investigativas, e elas podem ser mais ou menos direcionadas pelo professor dependendo do conhecimento que os alunos possuem ou de seu objetivo pedagógico.

Apesar de os discursos defensores da associação entre investigação e ensino de Ciências existirem há muito tempo, não significa que essa associação seja uma prática amplamente utilizada em sala de aula. Mesmo que propostas curriculares explicitem a sua importância no cotidiano escolar, professores podem se mostrar pouco adeptos à sua implementação, devido a uma série de motivos. Dentre eles, está a preocupação em ensinar fatos e conceitos, bem como conteúdos que serão cobrados em testes (WELCH et al., 1981).

Windschitl (2003) comenta que a investigação é a experiência 'quintessencial' da ciência, e, mesmo assim, professores, especialmente em início de carreira, não trabalham com investigação em suas classes e tampouco introduzem questões de interesse dos alunos que podem ser respondidas através dela.

Podendo a implementação da investigação no ensino de Ciências ser considerada como um desafio, seria relevante que pesquisadores se debruçassem sobre o contexto brasileiro e verificassem como esse aspecto se dá nesse cenário.

As pesquisas encontradas em importantes periódicos científicos nacionais vêm discutindo elementos relacionados às atividades investigativas nas aulas de Ciências. Alguns trabalhos trazem reflexões teóricas a respeito do ensino por investigação, discutindo seus objetivos e possibilidades (GALIAZZI; MORAES, 2002; GOMES; BORGES; JUSTI, 2008; MUNFORD; LIMA, 2007); outros centram suas pesquisas nos alunos, seja quanto às suas expectativas e opiniões sobre as atividades investigativas (BOSSLER et al., 2009; FERNANDES; SILVA, 2004), ou quanto ao seu desempenho decorrente das mesmas (BORGES; RODRIGUES, 2005; JÚLIO; VAZ, 2007; LOCATELLI; CARVALHO, 2007).

Quando o tema é o professor e sua relação com a atividade investigativa, há pesquisadores que se interessam por verificar as razões pelas quais esses docentes optam por agregar atividades práticas em suas aulas (LABURÚ, 2005) ou o papel desses professores na promoção de aprendizagens específicas, como a construção da representação gráfica durante as aulas investigativas (CARMO; CARVALHO, 2009).

Diante da carência de investigações que visem verificar quais os desafios que os professores enfrentam ao inserirem projetos investigativos em suas aulas, o presente trabalho pretende dedicar-se a esse tema, ampliando o referido quadro de pesquisas. 
Gouw, A. M. S.; Franzolin, F.; Fejes, M. E.

\section{Algumas considerações sobre a investigação e a experimentação no ensino de Ciências brasileiro e possíveis categorias de atividades investigativas}

O modelo de transmissão de conhecimento marcou o Ensino de Ciências no Brasil até meados da década de 1950, onde aulas teóricas reforçavam as características positivas da ciência e apresentavam o conhecimento científico como um produto final, uma verdade já pronta e absoluta (DELIZOICOV; ANGOTTI, 2000; KRASILCHIK, 1987). Entretanto, o período da guerra fria trouxe preocupações voltadas à atualização do conhecimento científico, o que gerou repercussões no ensino de Ciências: o ensino deveria ser atualizado e atividades de laboratório passaram a ser reivindicadas (KRASILCHIK, 1987). Surgiram, assim, os projetos de primeira geração do ensino de Química, Física, Biologia e Matemática, que visavam formar pequenos cientistas e identificar talentos para a área científica (KRASILCHIK, 2000).

Delizoicov e Angotti (2000) descrevem que a implantação desses projetos favoreceu o uso da instrução programada, do ensino por módulos e de atividades experimentais, enfatizando, assim, o chamado 'método da redescoberta', que envolvia uma sucessão de atividades que imitavam o trabalho dos cientistas.

Krasilchik (2000, p. 88) declara também que:

[...] as aulas práticas no ensino de Ciências servem a diferentes funções para diversas concepções do papel da escola e da forma de aprendizagem. No caso de um currículo que focaliza primordialmente a transmissão de informações, o trabalho em laboratório é motivador da aprendizagem, levando ao desenvolvimento de habilidades técnicas e principalmente auxiliando a fixação, o conhecimento sobre os fenômenos e fatos.

De acordo com Bizzo (1998, p. 76-77), há experimentos que são exploratórios, ou seja, que não possuem um resultado predeterminado. Um exemplo dado pelo autor é o de quando o professor pede para os alunos coletarem insetos que encontram em suas casas. Nesse caso, não é possível saber anteriormente o resultado da investigação, pois é impossível prever com exatidão quais insetos serão encontrados por cada aluno. Outro tipo de experimento mencionado pelo autor seriam as demonstrações, por meio das quais os alunos verificam, na prática, a ocorrência de um processo ou fenômeno.

Assim, observam-se diferentes tipos de aulas práticas de Ciências: de experimentos de natureza demonstrativa ou ilustrativa, em situações que imitam a atuação dos cientistas, a atividades cuja preocupação é a busca de soluções para questões desconhecidas. A essas atividades, muitas vezes, dá-se o nome de investigações.

As atividades investigativas podem ter diferentes níveis. Geli (1995 apud CAMPOS, 1999, p. 135) aponta algumas dessas diferenças quanto à definição do problema, seu desenvolvimento e a resposta: a) o problema, seu desenvolvimento e resposta podem ser definidos pelo professor ou pelo livro didático; b) o problema e seu desenvolvimento podem ser definidos pelo professor ou pelo livro didático, porém, com resposta aberta; c) o problema pode ser definido pelo professor ou pelo livro didático, porém, seu desenvolvimento e resposta são abertos, e d) o problema, seu desenvolvimento e resposta são abertos. 


\section{O ensino como investigação por meio de modelos de aprendizagem participativa}

Dentre as novas abordagens no ensino de Ciências que procuram contemplar uma cultura que engaje os estudantes na linguagem e nas formas de investigação científica autêntica, estão os modelos de aprendizagem participativa (BARAB et al., 2000; BARAB; HAY, 2001; BARAB; LUEHMANN, 2003; GOLICK et al., 2003).

Barab e Hay (2001) enumeraram algumas características interessantes relacionadas a esses modelos: os alunos não apenas ouvem relatos sobre fatos científicos a fim de receberem uma nota, mas fazem práticas, construídas e negociadas socialmente, relacionadas a determinados domínios de conhecimento, para solucionar dilemas e problemas a eles relacionados; o professor se desloca do eixo de transmissor de conhecimento para o de orientador e supervisor; e os problemas a resolver tendem a não são ser mais os propostos pelo livro didático ou pelo professor, mas, sobretudo, autênticos e estudados pelos alunos em resposta a necessidades do mundo real.

Os ambientes de aprendizagem propostos por essas novas abordagens mudam da memorização de fatos descontextualizados e habilidades descritas pelo professor à apropriação de práticas socialmente contextualizadas da comunidade. As motivações mudam da obtenção de notas em provas para o direcionamento de necessidades autênticas identificadas pelas comunidades através de práticas verdadeiras e factíveis (BARAB; HAY, 2001).

A Ciência nas escolas de Ensino Fundamental, sob essa perspectiva, deveria fazer parte da busca humana de compreensão do mundo, ao oferecer uma maneira de conhecer e fazer, que oriente os estudantes no percurso desse processo. De uma perspectiva pedagógica, essa mudança de abordagem envolve estratégias de ensino e currículos que incorporem o conteúdo em contextos ricos em investigação, através dos quais os alunos venham a apreciar tanto os conteúdos a serem aprendidos quanto as situações em que eles tenham valor (BARAB; LUEHMANN, 2003).

Dessa forma, o trabalho pedagógico passa a focalizar o desenvolvimento de habilidades básicas da investigação, dentre as quais: a compreensão e análise de dados empíricos, a solução de problemas, e a tomada de decisões, favorecendo o protagonismo e a autonomia do aluno no processo de aprendizagem (PERKINS, 1998).

Assim, diversos projetos de ensino, inovações curriculares e sequências didáticas que priorizam os pressupostos descritos acima vêm sendo implementados na disciplina de Ciências em escolas de Ensino Fundamental (BARAB et al., 2000; BARAB; HAY, 2001; BARAB; LUEHMANN, 2003; GOLICK et al., 2003). Porém, em contrapartida com as expectativas de que essas iniciativas tragam inovações positivas à sala de aula, Squire et al. (2003) declaram que um dos problemas relacionados à implementação dessas inovações é o fato de que muitos professores o fazem segundo as antigas metodologias de ensino.

Portanto, há questões, que merecem ser discutidas, relacionadas aos fatores que interferem na implementação dessas propostas inovadoras na sala de aula: como essas propostas são contextualizadas pelos professores para se adequarem à realidade da escola, e como o contexto cultural existente na sala de aula interage com tais propostas?

Para contemplar essas questões, analisamos, nessa pesquisa, a implementação de um projeto de ensino de Ciências por dois professores diferentes. Procuramos verificar, em cada 
Gouw, A. M. S.; Franzolin, F.; Fejes, M. E.

caso, o perfil dos professores e como eles costumavam organizar suas práticas pedagógicas antes da implementação. Os resultados obtidos revelam pontos interessantes que merecem ser considerados na implementação de propostas de ensino de Ciências de caráter investigativo.

\section{A cultura local na implementação de projetos de ensino: diferentes contextos, diferentes projetos}

Nos últimos anos, a Ciência da aprendizagem tem se tornado adepta de pesquisas, em pequena escala, focadas em projetos curriculares aplicados em contextos particulares. Esse tipo de pesquisa, que envolve um número pequeno de professores e alunos, tem trazido valiosos dados, em especial sobre as estratégias utilizadas pelo professor em prol da aprendizagem de seus alunos (SQUIRE et al., 2003).

Squire et al. (2003), ao relatarem como quatro professores diferentes implementaram um projeto de ensino de Ciências relacionado à qualidade do ar, indicam que a implementação do projeto é um fenômeno local sujeito: às necessidades dos estudantes, às necessidades dos professores, aos objetivos dos professores, às restrições locais e aos valores pedagógicos dos professores. Cada um dos quatro professores reorganizou o projeto à sua maneira, adaptando a proposta às necessidades locais, o que favoreceu um maior engajamento dos alunos. Para isso, as ferramentas disponíveis à implementação do projeto foram rearranjadas pelos professores. Assim, os autores esclarecem a importância de se levarem em conta as necessidades e experiências dos professores na elaboração de projetos de ensino.

Windschitl (2003) comenta que professores iniciantes não costumam trabalhar com projetos investigativos nas suas classes, o que limita sua participação quando convidados a participarem de programas dessa natureza. Mesmo no caso daqueles que trabalham com projetos investigativos em suas classes, os projetos não se configuram investigações autênticas. Para o autor, o trabalho com projetos investigativos está associado às experiências prévias dos professores e é fator determinante para o ensino através de investigações autênticas.

Barab e Luehmann (2003) comentam sobre o grande desafio de se implementarem projetos de ensino investigativos e inovadores que venham ao encontro das necessidades diárias dos professores. Para isso, os elaboradores de projetos devem fazê-los de forma que sejam flexíveis, e permitam, ao professor, sua 'customização' de acordo com as circunstâncias locais. Mais ainda, os autores consideram importante que os projetos permitam um diálogo entre seus elaboradores e aplicadores, a fim de que os professores possam aplicá-lo à sua maneira.

\section{$O$ contexto da pesquisa}

Sob a perspectiva da aprendizagem participativa e do Ensino de Ciências associado às atividades envolvendo investigação, o grupo de Ensino de Ciências do Núcleo de Apoio à Pesquisa (NAP) Escola do Futuro (vinculado à Pró-Reitoria de Pesquisa da Universidade de São Paulo) desenvolveu um projeto de ensino de Ciências de caráter investigativo, voltado ao estudo da biodiversidade da avifauna na escola, chamado Projeto Aves.

O projeto Aves tinha como objetivo proporcionar, aos alunos, a investigação das aves que visitam a escola, bem como seus hábitos alimentares. Para isso, o professor fazia a adesão ao projeto de forma voluntária. Ele recebia uma apostila com a metodologia proposta e as 
investigações possíveis de serem realizadas. Os alunos recebiam uma ficha para a obtenção de dados sobre as aves, observavam os hábitos de alimentação e nidificação e, ainda, elegiam temas de interesse para outras investigações. Dessa forma, os alunos travavam contato com a realidade da escola e propunham questões que podiam ser, de fato, investigadas de forma autêntica. Além disso, o projeto propunha o intercâmbio de ideias e dados por meio da internet, através de um site, um banco de dados virtual construído pelos alunos, e de um fórum de discussão on-line (BIZZO; OTHERO, 2000; FEJES et al., 2004; FEJES et al., 2006).

Antes da implementação, os professores participaram de encontros com os pesquisadores do grupo de ensino de Ciências do NAP Escola do Futuro, para a discussão da metodologia de ensino proposta. Nesses encontros se discutia, em especial, como as questões ou problemas apresentados pelos próprios alunos podem nortear o planejamento e o desenvolvimento das práticas de sala de aula. Além disso, eram tratadas questões próprias da investigação científica, tais como: o levantamento de hipóteses, a coleta de dados, a obtenção de conclusões etc. (FEJES et al., 2005).

\section{Metodologia}

Este estudo foi realizado a partir dos pressupostos da pesquisa qualitativa descritos por Bogdan e Biklen (1994). Tais autores apontam algumas características pertinentes à investigação qualitativa, as quais são consideradas, em menor ou maior grau, pelos pesquisadores que optam por essa abordagem: 1) A fonte de dados é o ambiente natural, sendo o investigador o principal instrumento; 2) A pesquisa é descritiva; 3) O interesse pelo processo é maior do que pelo produto ou resultados; 4) A análise dos dados é realizada de forma indutiva, e 5) O significado é o foco de atenção do pesquisador. Assim, esta pesquisa procurou analisar, de forma descritiva, como os professores implementaram o projeto de ensino Aves em suas turmas, e quais os desafios por eles enfrentados.

Os dados que subsidiaram esta pesquisa foram obtidos por meio de fontes primárias e secundárias. Sobre os dados obtidos através de fonte primária, foram realizadas entrevistas e questionários escritos. As entrevistas foram semiestruturadas, realizadas ao final do ano letivo, o que permitiu, aos professores entrevistados, discorrerem sobre o tema proposto de forma livre e flexível. As entrevistas também favoreceram a reflexão sobre o trabalho realizado ao longo do ano, de forma que os professores puderam também avaliar as atividades realizadas por eles.

Os questionários foram respondidos pelos professores durante os encontros de formação. Sua vantagem, nesta pesquisa, é a garantia de uma maior liberdade de resposta, uma vez que eram de natureza individual e não eram divulgados durante os encontros. Através dos questionários, puderam-se conhecer as práticas pedagógicas dos professores e sua relação com a equipe pedagógica da escola (BONI; QUARESMA, 2005; LUDKE; ANDRÉ, 1986).

Sobre os dados obtidos mediante fonte secundária, destacamos a análise de alguns documentos que permitiram compreender o planejamento e desenvolvimento pedagógico do projeto, a saber: portfólios produzidos pelos professores e por suas turmas durante a implementação do projeto Aves; e registros de diversas naturezas produzidos pelos alunos, tais como: cartazes, fichas de trabalho e relatórios. Além das fontes mencionadas acima, os pesqui- 
Gouw, A. M. S.; Franzolin, F.; Fejes, M. E.

sadores realizaram diversas observações pontuais junto às turmas dos professores durante as aulas em que o projeto foi discutido.

\section{Os professores participantes da pesquisa}

Foram selecionados, para esta pesquisa, dois professores de áreas e turmas bastante distintas: uma professora polivalente de Ensino Fundamental I (EFI) e um professor de Física de Ensino Fundamental II (EFII). Os dois professores lecionavam, na época da pesquisa, em escolas públicas do estado de São Paulo e participaram de todos os encontros de formação destinados à implementação da metodologia proposta. É interessante destacar que os encontros, apesar de com professores distintos, tinham uma mesma pauta de atividades.

\section{Caso 1. Professora de Ensino Fundamental I}

Professora ingressante na carreira de professor de Ensino Fundamental I. Tinha experiência na docência apenas com alfabetização de adultos. Ela implementou o projeto junto a uma turma de $1^{\circ}$ ano (cinco-seis anos). Por ser uma professora polivalente, sua prática pedagógica não tinha como foco a disciplina de Ciências e, sim, a alfabetização e o ensino da Matemática. Ela costumava trabalhar textos de Ciências nas aulas de Língua Portuguesa para tentar abranger o conteúdo científico. Em relação à prática docente de Ciências, a professora apontou que não teve formação inicial apropriada para lidar com os conteúdos científicos e por isso, tinha receio em executar a proposta metodológica de ensino por investigação. A decisão em participar do projeto se deu como forma de incrementar a prática pedagógica relacionada ao ensino de ciências.

\section{Caso 2. Professor de Ensino Fundamental II}

O professor lecionava a disciplina de Ciências Naturais há 23 anos, e implementou o projeto junto ao $7^{\circ}$ ano do Ensino Fundamental II. Nos últimos dois anos, não havia participado de atividades de formação continuada. A prática pedagógica do professor era centrada em aulas expositivas e exercícios de fixação e revisão. Algumas atividades no laboratório de informática e experiências simples relacionadas ao conteúdo estudado eram realizadas eventualmente. O livro didático e alguns instrumentos audiovisuais costumavam ser utilizados nas aulas. O professor, geralmente, realizava todos os anos, como proposta metodológica inovadora, uma gincana de veículos movidos a ar com os alunos do $9^{\circ}$ ano. A decisão em participar da proposta se deu como forma de obter ferramentas para melhor desenvolver o curso de Ciências e como atualização pedagógica. Segundo o professor, os educadores estão diante de uma grande encruzilhada, pois as formas tradicionalmente consagradas de lousa e explanação oral já não se mostram suficientes para compartilhar os conhecimentos dos fenômenos naturais e das Ciências. 
Desafios enfrentados por professores ...

\section{Resultados}

\section{Descrição da implementação do projeto Aves junto às turmas}

\section{Caso 1. Professora de Ensino Fundamental I}

\section{Escolha da turma e forma de implementação}

O projeto foi implementado em contraturno, com alunos que optaram por participar do projeto como atividade extra. A coordenação pedagógica da escola escolheu previamente o projeto Aves para ser aplicado, no $1^{\circ}$ ano do EFI, como atividade extra, e os alunos interessados realizaram uma inscrição. Devido à pouca intimidade com a disciplina de Ciências, a professora optou por trabalhar o projeto de forma conjunta com outras duas professoras de EFI, que estavam participando de outros projetos investigativos também no período contraturno. O grande desafio da implementação, segundo a professora, foi o início: "Como iniciar o projeto de forma que o interesse venha dos próprios alunos?". Essa questão foi bastante abordada pelas professoras nos encontros com a equipe do NAP-Escola do Futuro USP, e como os alunos ainda estavam em fase de alfabetização, as professoras optaram por desenhos como forma de trabalhar os conhecimentos prévios dos alunos sobre o tema aves. Assim, os alunos deveriam desenhar alguma ave que eles já haviam observado. $\mathrm{O}$ fato de os alunos estarem iniciando sua vida escolar fez com a professora não se focasse apenas na observação de aves, mas, sim, nas questões em que os alunos tinham interesse e poderiam investigar.

\section{Desenhos como ponto de partida para o ensino através da investigação}

A partir dos desenhos feitos pelos alunos, a professora passou a discutir que elementos as aves têm em comum, em que tipo de ambiente vivem etc. Durante a observação dos desenhos, a professora questionava, por exemplo: a coloração das aves (já que houve aves coloridas e listradas), o ambiente (havia desenhos em que se observavam árvores, outros não) e os hábitos das aves. Após o primeiro desenho, a professora passou a organizar o que os alunos descobriram sobre as características comuns das aves, tais como sua anatomia externa e seus hábitos. Essas características foram elencadas em um cartaz elaborado pelos próprios alunos, com o auxílio da professora, que atuou como escriba.

\section{A investigação dos alunos do $1^{\circ}$ Ano de EFI}

Através das discussões sobre as aves desenhadas, as professoras passaram a anotar questões de interesse dos alunos sobre o tema, tais como: "Como as aves nascem?", "As aves têm dente?", “Como o pintinho respira dentro do ovo?”, e outras. Para cada uma dessas questões, a professora organizou uma aula em que os próprios alunos deveriam buscar as respostas. A professora descreveu estas descobertas na seguinte comunicação via fórum on-line do projeto:

Olá pessoal, Vocês sabiam que a ave têm [sic] um dentinho especial para quebrar o ovo? E que depois de uns dois dias ela perde esse dentinho? Vocês sabiam que o ovo têm [sic] um monte de furinhos que nós não vemos, mas que existem, permitindo as aves respirarem dentro do ovo????? Essas são as descobertas dos primeiros anos da escola, a partir da questão como as aves nascem. Para confirmar as desco- 
Gouw, A. M. S.; Franzolin, F.; Fejes, M. E.

bertas fizemos duas experiências uma sugerida pela aluna Julia e outra pesquisada por nós professores: 1. Material: vela, ovo e fósforo. Acenda a vela e coloque o ovo na frente. Quando o ovo foi fecundado dá pra ver o pintinho. 2. Material: uma bacia com água e um ovo. Mergulhe o ovo na água. Vai formar bolbas em volta do ovo é porque ele é poroso. Abraços, Prof. 1.

Assim, mediante pesquisas bibliográficas e experimentos simples pesquisados pelas próprias professoras ou sugeridos pelos alunos, a turma passou a investigar suas próprias questões sobre as aves. Após o término do trabalho com os alunos do $1^{\circ}$ ano, a professora fez algumas colocações interessantes sobre a investigação junto aos alunos:

O fato dos próprios alunos trazerem as questões a serem investigadas cativa os alunos.

Seria interessante trabalhar conteúdos de acordo com questões levantadas pelos próprios alunos.

Os alunos discutem sobre suas questões e chegam às suas próprias conclusões.

A ideia de trabalhar com hipóteses, seguir o interesse deles: é mais trabalhoso, mais demorado, não é todo mundo que tem abertura para isso, mas é mais significativo para os alunos.

A professora ainda declarou que as informações fornecidas na apostila do projeto eram muito específicas, voltadas para alunos de EFII, e, portanto, pouco acessíveis a ela e a sua equipe, o que fez com que não a usassem. A ficha de observação de aves não era adequada aos alunos pequenos, devido ao nível de detalhamento e forma de preenchimento. Também o uso do fórum on-line foi limitado às professoras, que relataram as atividades desenvolvidas pelos alunos, uma vez que eles estavam em fase de alfabetização. Os relatos, porém, eram textos coletivos, elaborados com os alunos.

\section{Caso 2. Professor de Ensino Fundamental II}

\section{Escolha da turma e forma de implementação}

O professor escolheu a turma que iria trabalhar o projeto, $7^{\circ}$ ano do EFII, devido ao tema ser parte do currículo da série. O projeto foi aplicado durante o turno regular, de forma que uma aula de Ciências por semana foi reservada para o projeto. Fato que merece ser destacado é que o professor só deu prosseguimento ao projeto quando se assegurou de que a turma estava de fato interessada em participar. Não havendo interesse, o professor iria modificar a turma, o que não foi necessário. Alguns alunos do $8^{\circ}$ ano também demonstraram interesse em participar do projeto, e, por isso, o projeto se estendeu a eles. O professor teve como foco a observação de aves, e, para isso, organizou a sala em duplas e bases de observação (B.O.). Os alunos da escola eram oriundos de diversos bairros do município, por isso, cada B.O. contemplava um bairro distinto da cidade. Outra questão interessante planejada pelo professor foi que as atividades de observação, catalogação e pesquisa seriam realizadas pelos alunos nos seus bairros, em horários livres, e não durante as aulas. As aulas eram utilizadas como encontros de discussão e para utilizar o fórum on-line. O professor declarou que o trabalho com um 
projeto de caráter investigativo demandava grande necessidade de improviso, e por receio de o trabalho ser prejudicado, preferia trabalhar sozinho ao invés de trabalhar com outros professores. O professor também organizou uma visita ao Parque Estadual da Serra do Mar para que os alunos exercitassem a observação de aves.

\section{A investigação dos alunos do $7^{\circ} / 8^{\circ}$ ano do EFII}

Os alunos passaram a observar as aves que encontravam tanto no caminho para a escola, como no bairro em que viviam. Além disso, passaram a ter uma rotina de utilização do fórum on-line para contar sobre os animais que observavam. A escola, localizada ao lado da Serra do Mar, era visitada constantemente por diversas aves, inclusive tucanos, como pôde ser observado em uma mensagem postada por uma aluna no fórum on-line.

Após a fase de observação e relatos das observações, os alunos elaboraram um guia das aves observadas. O guia continha uma ficha com a foto da ave e uma descrição de suas características, nome etc.

Após o término do trabalho com os alunos do $7^{\circ}$ e $8^{\circ}$ anos, o professor apontou algumas questões pertinentes ao trabalho realizado. Uma delas foi o fato de que o trabalho com o projeto deixava os alunos 'soltos', e o fato de ele não conseguir acompanhar todas as manifestações dos alunos, sobretudo as realizadas via internet, causou certo desconforto. $\mathrm{O}$ professor também se viu com muitos dados de observação dos alunos, porém com angústia de não vê-los traduzidos em algum tipo de produto. Por isso, foi sugerida a ele a elaboração de um guia local de aves.

\section{Discussão e conclusões}

É necessário destacar, primeiramente, que ambos os professores passaram pelos mesmos encontros de formação continuada, com as mesmas atividades e pauta de discussões. $O$ projeto de ensino implementado por eles também foi o mesmo, que tinha uma apostila única e o mesmo site na internet.

O primeiro grande desafio enfrentado pela professora de EFI foi sua própria formação inicial: seu curso de Pedagogia não abordou, em profundidade, práticas de ensino de Ciências, o que gerou insegurança ao tratar da disciplina e seu 'confinamento' a atividades de leitura. Assim, diante de uma proposta de caráter investigativo, a professora se viu diante de um dilema. Para solucioná-lo, ela viu a necessidade de planejar e preparar detalhadamente todas as aulas e atividades inerentes ao projeto. A professora também teve mais segurança quando passou a planejar as aulas em conjunto com outras professoras. $\mathrm{O}$ trabalho em equipe foi essencial para a participação da professora, e, provavelmente sem ele, a professora não prosseguiria com a proposta.

A atividade prática realizada por ela para verificar a questão relacionada à respiração da ave dentro do ovo foi de natureza demonstrativa, na qual já se esperava uma resposta, e pretendia-se, a partir da mesma, demonstrar como tal fenômeno ocorre (BIZZO, 1998). Recorrendo à classificação de Geli (1995), nesse caso, a atividade investigativa não se enquadrou em nenhuma das quatro categorias, uma vez que o problema foi aberto, porém seu desenvolvimento e resposta foram definidos pela professora. Entretanto, houve também a oportunida- 
de de as crianças proporem atividades, como verificado no experimento do ovo com a vela, situação que se enquadra na categoria 'd', onde todos os elementos (desenvolvimento, problema e resposta) são abertos, apesar de a criança, provavelmente, ter suas sugestões influenciadas por alguma outra fonte.

Já do ponto de vista de Barab e Hay (2001), a professora organizou atividades que favoreceram a aprendizagem participativa, uma vez que as práticas foram negociadas entre os alunos da turma para solucionar problemas a eles relacionados. Seu papel não foi apenas de transmissora do conhecimento, mas de orientadora, e os problemas investigados foram propostos pelos alunos.

É interessante destacar, também, a estratégia utilizada pela professora para trazer alunos de tão pouca idade à discussão do tema aves: os desenhos. Os desenhos permitiram que a professora explorasse os conhecimentos prévios dos alunos e as questões norteadoras das investigações realizadas.

Assim, o projeto Aves, para a turma de $1^{\circ}$ ano de Ensino Fundamental I, envolveu atividades muitas vezes chamadas de 'método da redescoberta', porém com um caráter diferenciado, já que foram os próprios alunos quem elencaram os problemas a serem solucionados.

Já o professor de Ensino Fundamental II teve como grande desafio adequar o projeto à sua rotina de sala de aula. Para ele, o compromisso em abordar todo o planejamento proposto não poderia ser rompido com sua adesão ao projeto. Para isso, ele selecionou uma de suas aulas para a discussão do projeto e procurou organizar as atividades de forma que priorizassem a autonomia dos alunos: as bases de observação de aves não eram na escola, e sim nos bairros onde eles residiam, e as observações eram feitas em horários livres. Essa organização teve duas implicações para a prática do professor: não rompeu em definitivo sua prática e favoreceu a autonomia dos alunos durante as atividades investigativas, uma vez que não eram supervisionadas diretamente pelo professor, apenas discutidas em classe após sua realização. Ao contrário da professora, que organizou a maioria das atividades a serem realizadas, o professor trabalhou com o improviso, discutindo junto dos alunos as atividades realizadas.

Assim, pode-se perceber que as atividades práticas propostas pelo professor foram de caráter exploratório (BIZZO, 1998), uma vez que não possuíam um resultado previamente determinado. Já segundo a classificação de Geli (1995), o problema foi determinado pelo professor, porém seu desenvolvimento e respostas foram abertos (nível c).

Segundo os parâmetros de Barab e Hay (2001), o professor organizou as atividades de forma a contemplar a aprendizagem participativa, uma vez que as práticas foram negociadas e construídas entre ele e a turma. Seus papéis foram, principalmente, os de supervisor e orientador, e os problemas foram autênticos, relacionados ao mundo real: as aves que os alunos encontravam em seu cotidiano.

Os resultados desta pesquisa apontam que é possível trabalhar com atividades investigativas, tanto com alunos de pouca idade como maiores, utilizando-se, para isso, estratégias adequadas a cada faixa etária. Para os professores, a escolha de estratégias didáticas foi um desafio para que as atividades investigativas se aproximassem dos modelos de aprendizagem participativa.

O tempo de experiência no magistério dos professores também apontou questões interessantes: a professora, mesmo iniciante, encontrou uma forma de introduzir a questão da investigação, utilizando estratégias onde ela se sentia segura. No caso, ela preparou minuciosa- 
mente todas as atividades, para que as aulas pudessem ser dirigidas por ela com eficiência; já o professor não se preocupou muito com essa questão, ele organizou as atividades de forma a favorecer a autonomia do aluno. O trabalho em equipe também foi importante para a professora, e pode ser uma interessante estratégia para que o professor iniciante possa organizar atividades dessa natureza.

Apesar de utilizarem estratégias diferentes, foi possível verificar que ambos os professores conseguiram despertar o interesse dos alunos, uma vez que esses se mostraram engajados em suas investigações. Ademais, ainda como parte do processo de investigação, as atividades utilizadas por ambos - a construção de textos coletivos, desenhos, fichas que resumem as características das aves e a participação em discussões no fórum - propiciaram, aos alunos, compartilharem seus dados, observações e conclusões.

Por fim, percebeu-se também que o mesmo projeto de ensino foi implementado de maneira bastante distinta entre um professor e outro. Segundo Barab e Luehmann (2003), cada um dos professores customizou o projeto à sua maneira, considerando sua experiência no magistério e a turma com a qual iria trabalhar. No caso em questão, podemos dizer que cada professor atuou como coautor, uma vez que todos propuseram abordagens pedagógicas autênticas e únicas ao problema didático proposto.

Assim, verifica-se que as propostas de atividades investigativas devem ser flexíveis, propiciando que professores com diferentes formações e experiências possam adequá-las a sua realidade de forma segura e com satisfação. A observação dos resultados e dos produtos do trabalho são fatores que os professores observam como reconhecimento do seu sucesso no trabalho realizado.

\section{Referências}

BARAB, S. A. et al. Virtual solar system project: building understanding through model building. Journal of Research in Science Teaching, New York, v. 37, n. 7, p. 719-756, 2000 .

BARAB, S. A.; HAY, K. E. Doing science at the elbows of scientists: issues related to the scientist apprentice camp. Journal of Research in Science Teaching, New York, v. 38, n. 1, p. 70-102, 2001.

BARAB, S. A.; LUEHMANN, A. L. Building sustainable science curriculum: acknowledging and accommodating local adaptation. Science Education, Salem, v. 87, n. 4, p. 454-467, 2003.

BIZZO, N. Ciências: fácil ou difícil? São Paulo: Ática, 1998.

BIZZO, N.; OTHERO, F. O “método dos projetos" no ensino de Ciências: reflexões sobre seis anos de aplicação. In: VII ENCONTRO PERSPECTIVAS DO ENSINO DE BIOLOGIA, 7. E SIMPÓSIO LATINO-AMERICANO DA IOSTE, 1., 2000, São Paulo. Anais... São Paulo: FEUSP, 2000. p. 807-809. 
Gouw, A. M. S.; Franzolin, F.; Fejes, M. E.

BOGDAN, R.; BIKLEN, S. Investigação qualitativa em educação: uma introdução à teoria e aos métodos. Porto: Porto Editora, 1994.

BONI, V.; QUARESMA, S. J. Aprendendo a entrevistar: como fazer entrevistas em ciências sociais. Em Tese: revista eletrônica dos pós-graduandos em sociologia política da UFSC, Florianópolis, v. 2, n. 1, p. 68-80, 2005.

BORGES, A. T.; RODRIGUES, B. A. O ensino da física do som baseado em investigações. Ensaio: pesquisa em educação em ciências, Belo Horizonte, v. 7, n. 2, p. 1-24, 2005.

BOSSLER, A. P. et al. O estudo das vozes de alunos quando estão envolvidos em atividades de investigação em aulas de Física. Ensaio: pesquisa em educação em ciências, Belo Horizonte, v. 11, n. 2, p. 301-319, 2009.

BRASIL. Secretaria de Educação Fundamental. Parâmetros curriculares nacionais: ciências naturais. Brasília, 1997.

. Ministério da Educação e do Desporto. Referencial curricular nacional para a educação infantil: conhecimento de mundo. Brasilia, 1998.

BYBEE, R. W. Teaching science as inquiry. In: MINSTRELL, J.; VAN ZEE, E. Inquiring into inquiry learning and teaching in science. Washington: American Association for the Advancement of Science, 2000. p. 21-46.

CAMPOS, M. C. C. Didática de ciências: o ensino-aprendizagem como investigação. São Paulo: FTD, 1999.

CARMO, A. B.; CARVALHO, A. M. P. Construindo a linguagem gráfica em uma aula experimental de física. Ciência \& Educação, Bauru, v. 15, n. 1, p. 61-84, 2009.

DELIZOICOV, D.; ANGOTTI, J. A. Metodologia do ensino de ciências. 2. ed. São Paulo: Cortez, 2000.

FEJES, M. et al. Implementación de proyectos de investigación en ciencias vía telemática. Novedades Educativas: ideas y recursos, Buenos Aires, v. 16, n. 163, p. 04-09, 2004.

O uso de ferramentas de comunicação a distância: uma experiência no ensino de ciências. E-duc@ção Virtual, Itajaí, v. 2, p. 01-08, 2006.

Avaliação da participação em projetos de ensino de ciências via telemática: uma visão de alunos e professores. Enseñanza de las Ciencias, Barcelona, p. 1-5, 2005. (Número extra).

FERNANDES, M. M.; SILVA, M. H. S. O trabalho experimental de investigação: das expectativas dos alunos às potencialidades no desenvolvimento de competências. Revista Brasileira de Pesquisa em Educação em Ciências, Belo Horizonte, v. 4, n. 1, p. 45-58, 2004. 
Desafios enfrentados por professores ...

GALIAZZI, M. C.; MORAES, R. Educação pela pesquisa como modo, tempo e espaço de qualificação da formação de professores de ciências. Ciência \& Educação, Bauru, v. 8, n. 2, p. 237-252, 2002.

GELI, A. M. C. La evaluación de los trabajos prácticos. Alambique: didáctica de las ciencias experimentales, Barcelona, n. 4, p. 25-32, 1995.

GOLICK, D. A. et al. Bumble boosters: students doing real science. Journal of Science Education and Technology, Dordrecht, v. 12, n. 2, p. 149-152, 2003.

GOMES, A. D.T.; BORGES, A. T.; JUSTI, R. Processos e conhecimentos envolvidos na realização de atividades práticas: revisão da literatura e implicações para a pesquisa. Investigações em Ensino de Ciências, Porto Alegre, v. 13, n. 2, p. 187-207, 2008.

JÚLIO, J. M.; VAZ, A. Grupos de alunos como grupos de trabalho: um estudo sobre atividades de investigação. Revista Brasileira de Pesquisa em Educação em Ciências, Belo Horizonte, v. 7, n. 2, p. 109-138, 2007.

KRASILCHIK, M. O professor e o currículo das ciências. São Paulo: EPU: Edusp, 1987.

Reformas e realidade: o caso do ensino de ciências. São Paulo em Perspectiva, São Paulo, v. 14, n. 1, p. 85-93, 2000.

LABURÚ, C. E. Seleção de experimentos de física no ensino médio: uma investigação a partir da fala de professores. Investigações em Ensino de Ciências, Porto Alegre, v. 10, n. 2, p. 161-178, 2005.

LOCATELLI, R. J.; CARVALHO, A. M. P. Uma análise do raciocínio utilizado pelos alunos ao resolverem os problemas propostos nas atividades de conhecimento físico. Revista Brasileira de Pesquisa em Educação em Ciências, Belo Horizonte, v. 7, n. 3, p. 1-18, 2007.

LUDKE, M.; ANDRÉ, M. E. D. A. Pesquisa em educação: abordagens qualitativas. São Paulo: E.P.U., 1986.

MUNFORD, D.; LIMA, M. E. C. C. Ensinar ciências por investigação: em quê estamos de acordo? Ensaio: pesquisa em educação em ciências, Belo Horizonte, v. 9, n. 1, p. 72-89, 2007.

NATIONAL RESEARCH COUNCIL. National science education standards. Washington: National Academy Press, 1996.

National science education standards: a guide for teaching and learning. Washington: National Academy Press, 2000.

PERKINS, D. What is understanding? In: WISKE, M. S. (Ed.). Teaching for understanding: linking research with practice. San Francisco: Jossey-Bass, 1998. p. 39-58. 
Gouw, A. M. S.; Franzolin, F.; Fejes, M. E.

SQUIRE, K. D. et al. Designed curriculum and local culture: acknowledging the primacy of classroom culture. Science Education, Salem. v. 87, n. 4, p. 468-489, 2003.

WELCH, W. W. et al. The role of inquiry in science education: analysis and recommendations. Science Education, Salem, v. 65, n. 1, p. 33-50, 1981.

WINDSCHITL, M. Inquiry projects in science teacher investigation: what can investigative experiences reveal about teacher thinking and eventual classroom practice? Science

Education, Salem, v. 87, n. 1, p. 112-143, 2003.

Artigo recebido em 18/06/12. Aceito em 03/10/12. 